\title{
Outcome of Unicompartmental Knee Arthroplasty: A Systematic Review of Comparative Studies between Fixed and Mobile Bearings Focusing on Complications
}

\author{
Young-Bong Ko, MD, Manan Ramesh Gujarathi, DNB (D’Orth), and Kwang-Jun Oh, MD \\ Department of Orthopaedic Surgery, Konkuk University Medical Center, Konkuk University School of Medicine, Seoul, Korea
}

\begin{abstract}
The purpose of this systematic review is to collate results of studies comparing fixed and mobile bearing unicompartmental knee arthroplasty (UKA), focusing on complications and timing for reoperations. Out of 723 results derived from PubMed, EMBASE and Cochrane database search engines on bearings in arthroplasty, 10 studies comparing clinical results of fixed bearings to mobile bearings in UKA were found eligible for analysis. The reoperation rate was calculated using a novel method such as reoperations per hundred component years, and the causes of specific reoperations were investigated. The overall reoperation rate per hundred component years was similar between the mobile bearings (1.392) and fixed bearings (1.377); however, mobile bearings were more susceptible to reoperations in cases with aseptic loosening $(0.393>0.255)$, progression of arthritis $(0.428>0.357)$ and implant dislocation $(0.286>0)$. The overall incidence of complications is similar for fixed and mobile bearing designs in UKA. The discussion on complications presented above may assist surgeons in their choice of bearing design.
\end{abstract}

Keywords: Knee, Unicompartmental arthroplasty, Postoperative complications, Prosthesis failure

\section{Introduction}

Unicompartmental knee arthroplasty (UKA) has currently evolved into the treatment of choice for localized arthritis of the knee in the middle-aged and elderly patients. However, the bearing modularity continues to incite debates since both bearings yield similar outcomes in spite of fundamentally different design concepts. Non-conforming articulating surfaces and restricted bearing motion inherent to fixed bearings predispose them to repetitive edge loading and peripheral wear ${ }^{1)}$. Highly conforming mobile bearings were designed to overcome these limitations;

Received January 20, 2015; Revised (1st) May 13, 2015;

(2nd) May 29, 2015; Accepted June 8, 2015

Correspondence to: Kwang-Jun Oh, MD

Department of Orthopaedic Surgery, Konkuk University Medical

Center, 120 Neungdong-ro, Gwangin-gu, Seoul 05030, Korea

Tel: +82-2-2030-7615, Fax: +82-2-2030-7749

E-mail: damioh@gmail.com

This is an Open Access article distributed under the terms of the Creative Commons Attribution Non-Commercial License (http://creativecommons.org/licenses/by-nc/4.0/) which permits unrestricted non-commercial use, distribution, and reproduction in any medium, provided the original work is properly cited. thus, it offers better restoration of natural kinematics of the knee and reduction of contact stress and wear ${ }^{2-4)}$. However, the superiority of mobile bearings to their predecessors is questionable, as concurrent advances in polyethylene processing, implant design and surgical technique enabled fixed bearings to offer competent results with a relatively forgiving technique ${ }^{5-8}$.

The first meta-analysis that attempted to resolve this debate was constrained by paucity of studies that could support a robust statistical analysis ${ }^{9}$. A recently reported meta-analysis employed thorough statistical analysis and reached a conclusion that shows no essential differences in revision rates between mobile and fixed bearings ${ }^{10}$. Both studies ${ }^{9,10)}$ faced the same limitations-paucity of randomized control trials (RCT) and variations in study objectives. For comparative analysis of data based on various sample sizes and follow-up periods, we calculated reoperation rates per hundred component years in this study.

Data pertaining to measures of survivorship and frequency and timing of failures was extracted and analyzed. We thought that the crux of the debate between fixed and mobile bearing UKA lies in propensity and timing of complications. Therefore, we focused on comparative analysis and discussion of complications. 


\section{Ko et al. Complications of Fixed and Mobile Bearings in UKA}

\section{Materials and Methods}

This review followed the guidelines of Preferred Reporting Items for Systematic reviews and Meta Analyses (PRISMA) ${ }^{11)}$. A search for articles was conducted on PubMed, Cochrane library and EMBASE for records available till June 2014. We used keywords such as "knee arthroplasty", "fixed", "mobile" and "bearing" and Boolean operators (AND, OR) for various combinations. All 723 studies comparing fixed and mobile medial UKAs were included, regardless of implant manufacturer, study period, study design, indication for surgery or language of reporting. A total of 169 unique titles were identified after elimination of duplicate results and screening for relevance. References in review papers and eligible studies were assessed manually. After stepwise exclusion of studies comparing in vivo behavior, retrieval analysis and cadaveric studies as shown in Fig. 1, only 10 comparative studies were found to be eligible. Since only three RCTs/ quasi-RCTs were found in our search, we included non-randomized comparative studies. After screening full text of the eligible studies, we formulated an analysis protocol that would ensure collection of all comparative data, including research methodology and level of evidence. One of the authors extracted data from each study regarding the number of patients, number of knees, study period, demographic data, implant, inclusion and exclusion criteria, indication for surgery, surgical technique, pre-operative scores, type of prosthesis, surgical approach, experience of surgeon and dura- tion of follow-up.

There were no differences in the indications for the mobile type and fixed type UKAs. The outcome measures included reason and incidence of reoperation, timing of reoperation and survivorship. All data was verified by another author and discrepancies and disagreements were resolved through discussion.

The structure of study, sample size, follow-up period and outcome measures were not consistent in the literature. To compare the diverse data, we calculated the number of reoperations per 100 observed component years, as described by the Australian arthroplasty registry ${ }^{12}$. In this study, we combined different follow-up periods and number of knees reported in every study to calculate the observed component years at risk for each bearing design. Cumulative reoperations and cause-specific reoperations were then compared to the denominator using a simple formula: reoperations per hundred component years $=$

$$
\frac{\text { number of reoperations for any reason } \times 100}{\text { total number of observed component years }}
$$

where the total number of observed component year $=\sum_{i=1}^{n}$ individual years from implantation.

Interpretation of results is fairly straightforward, such that the value of 1 implies reoperation rate of $1 \%$ per year, or $10 \%$ at ten years. To evaluate whether heterogeneity of data confounded our results, we created subgroups within eligible studies and calculated the same values for the subgroups for comparison with the

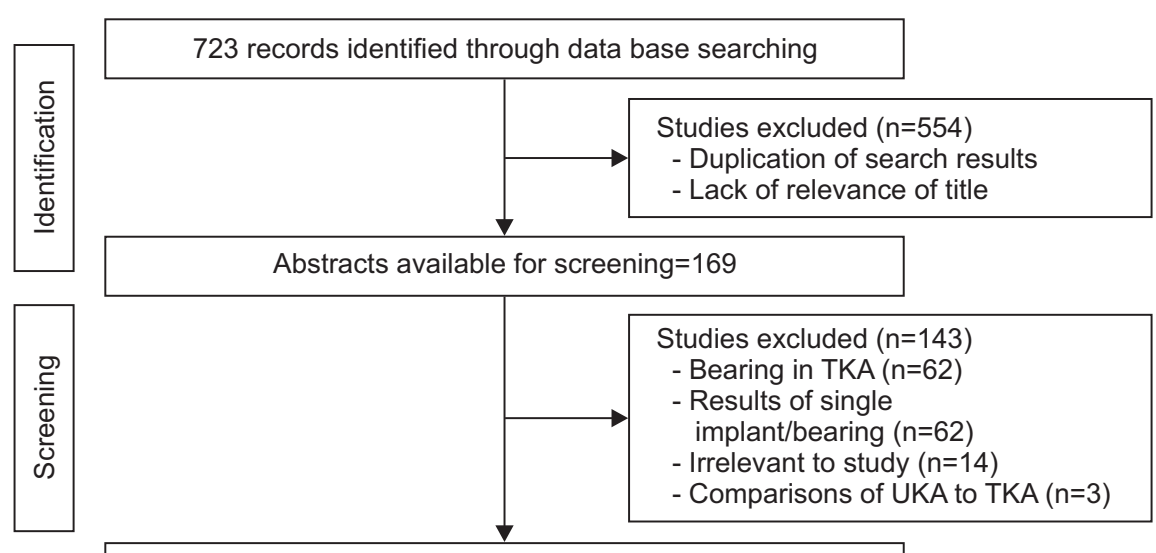

Full text articles assessed for eligibility $(n=26)$

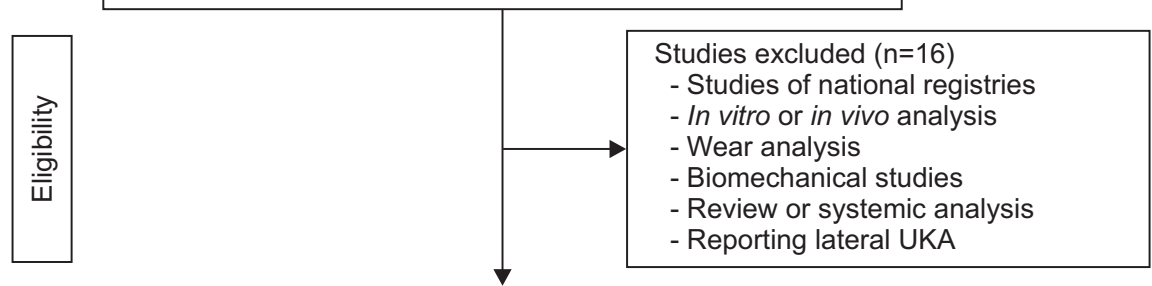

Comparative studies for meta-analysis $(n=10)$
Fig. 1. Flowchart for the identification of eligible studies. TKA: total knee arthroplasty, UKA: unicompartmental knee arthroplasty. 
cumulative results. The number of knees reported may imply results of a high volume center, while follow-up of more than three years may identify complications dependent on time since surgery. Subgroups were created within eligible studies based on these criteria and results compared with the cumulative mean.

\section{Results}

\section{Baseline Characteristics}

As indicated in Table 1, the review of 10 studies generated data on 1,019 knees in 887 patients ${ }^{5,8,13-20)}$. Fixed bearing UKAs were implanted in 595 knees of 515 patients and mobile bearing UKAs were implanted in 424 knees of 372 patients. All studies except one $^{20)}$ reported detailed demographic information and compared study populations for patient specific factors that may influence the outcome. The mean age of patients receiving fixed bearing UKA was 66.57 years (range, 33 to 88 years; standard deviation [SD], 2.28), while that in mobile bearing group was 65.08 years (range, 38 to 84 years; SD, 3.50). Women comprised 54\% of the patients in the fixed bearing group and $56 \%$ of the patients in the mobile bearing group. Body mass index (BMI) was reported in four studies ${ }^{13-16)}$ for a total of 324 fixed bearing knees and 221 mobile bearing knees. The average BMI in the fixed bearing group was $27.70 \mathrm{~kg} / \mathrm{m}^{2}$ (range, 16.8 to $44 \mathrm{~kg} / \mathrm{m}^{2} ; \mathrm{SD}, 1.15$ ), while that in the mobile bearing group was $29.24 \mathrm{~kg} / \mathrm{m}^{2}$ (range, 19.3 to $43.1 \mathrm{~kg} / \mathrm{m}^{2}$; SD, 2.04). The mean duration of follow-up in the fixed bearing group was $6.96 \pm 4.66$ years (range, 1.03 to 17.2 years), while that of mobile bearing group was $7.15 \pm 5.08$ years (range, 2 to 17.2 years).

Considerable variety existed in the implant used in the fixed bearing group-Miller-Galante (Zimmer Inc., Warsaw, IN, USA) was used in four studies ${ }^{13-16)}$, Robert Brigham (Johnson \& Johnson, Somerville, NJ, USA) in two studies ${ }^{8,20)}$ and St Georg Sled (Waldemar Link, Hamburg, Germany) ${ }^{5)}$, Preservation All Poly (DePuy, Warsaw, IN, USA) ${ }^{18)}$, Optetrak (Exactech, Gainesville, FL, USA) ${ }^{19)}$, Allegreto (Centerpulse, Baar, Switzerland) ${ }^{17)}$ were

Table 1. Baseline Characteristics of Studies and Participants

\begin{tabular}{|c|c|c|c|c|c|c|c|c|}
\hline \multirow{2}{*}{$\begin{array}{r}\text { Author } \\
\text { Gleeson et al. }^{5)}\end{array}$} & \multirow{2}{*}{$\begin{array}{c}\text { Type of study } \\
\text { (level of evidence) }\end{array}$} & \multicolumn{2}{|c|}{$\begin{array}{l}\text { No. of knees } \\
\text { (patients) }\end{array}$} & \multirow{2}{*}{$\begin{array}{c}\text { Mean/median } \\
\text { age }(\mathrm{yr})\end{array}$} & \multirow{2}{*}{$\begin{array}{l}\text { Gender } \\
\text { (M:F) } \\
29: 20\end{array}$} & \multirow[t]{2}{*}{$\begin{array}{l}\text { Body mass index } \\
\qquad\left(\mathrm{kg} / \mathrm{m}^{2}\right)\end{array}$} & \multirow{2}{*}{$\begin{array}{c}\text { Body weight } \\
(\mathrm{kg})\end{array}$} & \multirow{2}{*}{$\begin{array}{c}\begin{array}{c}\text { Follow-up duration } \\
\text { (yr) }\end{array} \\
4(2.7-5.3)\end{array}$} \\
\hline & & FB & $57(49)$ & & & & & \\
\hline & & $\mathrm{MB}$ & $47(43)$ & 64.7 & $17: 26$ & & 77.7 & $4(2.7-5.3)$ \\
\hline \multirow[t]{2}{*}{ Parratte et al. ${ }^{13)}$} & Retrospective (III) & $\mathrm{FB}$ & $79(75)$ & $62.8 \pm 9.2$ & $29: 50$ & $26 \pm 4$ & & $17.2 \pm 4.8(15-21.2)^{\mathrm{a})}$ \\
\hline & & $\mathrm{MB}$ & $77(72)$ & $63.4 \pm 11$ & $25: 52$ & $27 \pm 3$ & & $17.2 \pm 4.8(15-21.2)^{\mathrm{a})}$ \\
\hline \multirow[t]{2}{*}{ Biau et al. ${ }^{14), b)}$} & Retrospective (III) & $\mathrm{FB}$ & $67(57)$ & $66(59-71)$ & $33: 34$ & $28(27-32)$ & & $3.25(2.25-5)^{c)}$ \\
\hline & & $\mathrm{MB}$ & $37(33)$ & $60(55-65)$ & $15: 22$ & $32(29-34)$ & & $5.25(4.9-6.33)^{c)}$ \\
\hline \multirow[t]{2}{*}{ Li et al. ${ }^{15)}$} & RCT (I) & FB & $28(24)$ & 70 & $20: 8$ & 26.5 & & 2 \\
\hline & & $\mathrm{MB}$ & $28(24)$ & 74 & $20: 8$ & 27.6 & & 2 \\
\hline \multirow[t]{2}{*}{ Emerson et al. ${ }^{8)}$} & Retrospective (III) & $\mathrm{FB}$ & $51(45)$ & $63(33-84)$ & $18: 33$ & & $84.4(47.2-124.7)$ & $6.1(0.5-13.2)$ \\
\hline & & $\mathrm{MB}$ & $50(43)$ & $63(38-65)$ & $22: 28$ & & $79.4(50.8-108.9)$ & $6.8(2-10.9)$ \\
\hline \multirow[t]{2}{*}{ Whittaker et al. ${ }^{16)}$} & Retrospective (III) & FB & $150(117)$ & $68^{\text {d) }}(45-79)$ & $71: 79$ & $28.7(16.8-44)$ & & $8.1(1-17.8)$ \\
\hline & & $\mathrm{MB}$ & $79(62)$ & $63^{\text {d) }}(49-87)$ & $41: 38$ & $30.7(19.3-43.1)$ & & $3.9(1-11.3)$ \\
\hline \multirow[t]{2}{*}{ Confalonieri et al. ${ }^{17)}$} & RCT (I) & $\mathrm{FB}$ & $20(20)$ & $69.5(58-81)$ & $8: 12$ & NA & & $5.7^{\text {a) }}$ \\
\hline & & $\mathrm{MB}$ & $20(20)$ & $71(58-84)$ & $11: 19$ & NA & & $5.7^{\text {a) }}$ \\
\hline \multirow[t]{2}{*}{ Bhattacharya et al. ${ }^{18)}$} & Retrospective (III) & $\mathrm{FB}$ & $91(79)$ & $67.7(48-88)$ & $33: 46$ & NA & & $3.7(2-6.1)^{c)}$ \\
\hline & & MB & $49(44)$ & $68.8(50-83)$ & $22: 22$ & NA & & $5.6(2-9.9)^{c)}$ \\
\hline \multirow[t]{2}{*}{ Catani et al. ${ }^{19)}$} & Retrospective (III) & FB & $10(10)$ & $70.3 \pm 7.6$ & $4: 6$ & & $76.3 \pm 14.4$ & $1.03 \pm 0.6^{c)}$ \\
\hline & & $\mathrm{MB}$ & $10(10)$ & $70.3 \pm 5.8$ & $2: 8$ & & $75.4 \pm 11.9$ & $3.84 \pm 2.07^{\mathrm{c})}$ \\
\hline \multirow[t]{2}{*}{ Emerson et al. ${ }^{20)}$} & Retrospective (III) & FB & $42(39)$ & NA & NA & NA & NA & NA \\
\hline & & $\mathrm{MB}$ & $27(21)$ & & & & & \\
\hline
\end{tabular}

Values are presented as mean \pm standard deviation or median (range).

FB: fixed bearing, MB: mobile bearing, RCT: randomized controlled trial, NA: not available

${ }^{a)}$ Follow-up of fixed or mobile bearing is not mentioned separately. ${ }^{\text {b) }}$ Values are expressed as median (first quartile to third quartile). ${ }^{\text {c) Follow-up }}$ reported in months converted into years. ${ }^{\text {d) }}$ Values are expressed as median. 


\section{Ko et al. Complications of Fixed and Mobile Bearings in UKA}

used in one study each. In contrast, there was considerable uniformity in use of implant in the mobile bearing group. All studies utilized Oxford (Biomet, Warsaw, IN, USA) mobile bearing knee except Confalonieri et al. ${ }^{17)}$, who used AMC (Alphanorm, Quiershied, Germany) mobile bearing knee.

We found that most studies adjudged inclusion of participants based on criteria similar to Kozinn and Scott ${ }^{21)}$ criteria or Goodfellow's criteria $^{22)}$. Variations were observed in acceptable magnitude, and many studies added supplementary criteria depending on the objective of the study. However, these variations did not affect the internal validity of meta-analyses ${ }^{9,23)}$.

\section{Complications}

Reoperation rates were calculated in terms of hundred component years from eight studies ${ }^{5,8,13-18)}$ (Table 2). The overall reoperation rate of mobile bearing designs was almost the same as that of fixed bearing designs. There was no wear in the mo- bile bearing group; however, progression of arthritis and aseptic loosening were more frequent in the mobile bearing group. In contrast, wear was the main complication requiring reoperation in the fixed bearing group, and there was no bearing dislocation in the fixed bearing group. The overall average time to reoperation unrelated to infection was shorter for mobile bearings, while the time to reoperation due to aseptic loosening or tibial component subsidence was longer in the mobile bearing group than in the fixed bearing group ( 7.15 years and 5.95 years, respectively). The time to reoperation for progression of arthritis and persistent unexplained pain was similar between mobile and fixed bearing groups ( 7.44 years vs. 7.05 years and 3.25 years vs. 3.61 years, respectively). The timing of bearing dislocations in the mobile bearing group was 0.49 years after surgery and the time to reoperation for wear in the fixed bearing group was 8.59 years.

Table 2. Comparison of Reoperation Rates per 100 Component Years and Mean Time to Reoperation

\begin{tabular}{cllcccccc}
\hline \multicolumn{1}{c}{ Parameter } & Bearing & Overall ${ }^{\text {a) }}$ & $\begin{array}{c}\text { Progression of } \\
\text { arthritis }\end{array}$ & $\begin{array}{c}\text { Aseptic } \\
\text { loosening } \\
\text { or tibial } \\
\text { component } \\
\text { subsidence }\end{array}$ & $\begin{array}{c}\text { Bearing } \\
\text { dislocation }\end{array}$ & $\begin{array}{c}\text { Persistent } \\
\text { unexplained } \\
\text { pain }\end{array}$ & Infection & Wear \\
\hline $\begin{array}{c}\text { Reoperation rates per } \\
100 \text { component years }\end{array}$ & Fixed & 1.377 & 0.357 & 0.255 & 0 & 0.179 & 0.076 & 0.383 \\
Time to reoperation in & Fixed & 1.392 & 0.428 & 0.393 & 0.285 & 0.071 & 0.071 & 0 \\
years & Mobile & 5.79 & 7.05 & 5.95 & NA & 3.61 & 0.23 & 8.59 \\
\hline
\end{tabular}

NA: not available.

${ }^{a)}$ Infection was excluded in calculation of overall time to revision since two cases of infection were reported in the mobile bearing group at 0.125 and 12.9 years after surgery.

Table 3. Comparison of Reoperation Rates after Subgroup Analysis

\begin{tabular}{|c|c|c|c|c|c|c|c|c|c|c|}
\hline Parameter & Bearing & $\begin{array}{l}\text { No. of } \\
\text { knees }\end{array}$ & $\begin{array}{c}\text { Component } \\
\text { years }\end{array}$ & $\mathrm{R} / 100 \mathrm{CY}$ & $\begin{array}{l}\text { Progression } \\
\text { of arthritis }\end{array}$ & $\begin{array}{c}\text { Aseptic } \\
\text { loosening } \\
\text { or tibial } \\
\text { component } \\
\text { subsidence }\end{array}$ & $\begin{array}{l}\text { Bearing } \\
\text { dislocation }\end{array}$ & $\begin{array}{c}\text { Persistent } \\
\text { unexplained } \\
\text { pain }\end{array}$ & Infection & Wear \\
\hline \multirow[t]{2}{*}{$>100$ knees $^{5,8,13,14,16,18)}$} & Fixed & 495 & $3,750.97$ & 1.38 & 0.37 & 0.27 & 0 & 0.16 & 0.08 & 0.40 \\
\hline & Mobile & 339 & $2,630.77$ & 1.33 & 0.46 & 0.38 & 0.30 & 0.08 & 0.04 & 0 \\
\hline \multirow{2}{*}{$\begin{array}{l}\text { Follow-up }>3 \\
\text { years }^{5,8,13,14,16-18)}\end{array}$} & Fixed & 515 & $3,864.97$ & 1.37 & 0.36 & 0.26 & 0 & 0.18 & 0.08 & 0.18 \\
\hline & Mobile & 359 & $2,744.77$ & 1.28 & 0.44 & 0.36 & 0.29 & 0.07 & 0.04 & 0 \\
\hline \multirow{2}{*}{$\begin{array}{l}\text { Metal backed fixed } \\
\text { bearings }^{8,13,14,16)}\end{array}$} & Fixed & 395 & $3,354.00$ & 1.282 & 0.358 & 0.209 & 0 & 0.089 & 0.089 & 0.047 \\
\hline & Mobile & 291 & $2,336.75$ & 1.327 & 0.471 & 0.385 & 0.214 & 0 & 0.086 & 0 \\
\hline
\end{tabular}

$\mathrm{R} / 100 \mathrm{CY}$ : reoperations per 100 component years. 
Table 4. Comparison of Reoperation Rates of the Studies Using Miller-Galante as Fixed Bearing or Oxford Prosthesis as Mobile Bearing

\begin{tabular}{lccccccccc}
\hline \multicolumn{1}{c}{ Parameter } & $\begin{array}{c}\text { No. of } \\
\text { knees }\end{array}$ & $\begin{array}{c}\text { Component } \\
\text { years }\end{array}$ & R/100CY & $\begin{array}{c}\text { Progression } \\
\text { of arthritis }\end{array}$ & $\begin{array}{c}\text { Aseptic loosening } \\
\text { or tibial component } \\
\text { subsidence }\end{array}$ & $\begin{array}{c}\text { Bearing } \\
\text { dislocation }\end{array}$ & $\begin{array}{c}\text { Persistent } \\
\text { unexplained } \\
\text { pain }\end{array}$ & $\begin{array}{c}\text { Infection } \\
\text { Wear }\end{array}$ \\
\hline Miller-Galante $^{13-16)}$ & 324 & $2,847.55$ & 1.12 & 0.39 & 0.18 & 0 & 0.07 & 0.11 & 0.39 \\
Oxford $^{5,8,13-16,18,19)}$ & 377 & $2,725.20$ & 1.36 & 0.44 & 0.37 & 0.29 & 0.07 & 0.07 & 0 \\
\hline
\end{tabular}

R/100CY: reoperations per 100 component years.

\section{Subgroup Analysis}

Heterogeneity amongst analyzed studies may confound internal validity of the review. To verify if the results generated by a simplistic method of calculation are consistent, we sub-classified eligible studies into subgroups and calculated reoperation rates for comparison to the overall findings (Table 3). Pattern of reoperations was similar within the subgroups, suggesting that reoperations for aseptic loosening and progression of arthritis are indeed higher for mobile bearings while those for persistent unexplained pain and wear are higher for fixed bearings. In contrast with cumulative rates for entire study population, the overall reoperation rate of mobile bearings was lower than fixed bearings in studies reporting a total of more than 100 UKAs, as well as in studies reporting a follow-up of more than three years.

We performed another subgroups analysis for studies using Miller-Galante or Oxford prosthesis (Table 4).

The overall reoperation rate of mobile bearings was higher than fixed bearings. The reoperation rate for aseptic loosening was also higher for mobile bearings; however, only wear-related reoperation rate was higher for fixed bearings.

\section{Discussion}

There are many existing studies showing favorable results of mobile and fixed bearing UKAs ${ }^{10,24-30)}$. However these studies have reported the results of a single implant instead of comparison of fixed and mobile bearing designs; therefore, we included only comparative studies. Although, the follow-up periods of 10 eligible studies were not sufficient to compare the long-term outcomes of UKA, the results of our review have confirmed that mobile bearings provide low rates of wear. In addition, the differences in the indication between the bearing types have not been established.

Durability and survivorship are perhaps the main reasons of preference for total knee arthroplasty over UKAs in eligible patients. Improvement in survivorship may transform UKA from an interim procedure to a preferred primary treatment indicated at an optimal stage of arthritis. Therefore, a comparative evalua- tion of complications of different bearing designs and their timings in UKA is at the heart of this discussion.

Aseptic loosening, progression of arthritis and wear of polyethylene insert are the main complications requiring reoperation following UKA. Our results suggest that first two complications are more common in the knees with mobile bearings than fixed bearings. While no knees with mobile bearings were re-operated for wear, the most common complication requiring reoperation for mobile bearing UKA was progression of arthritis. Mobile bearings were found to generate wear with a smaller particulate size $(0.58 \mu \mathrm{m})$ but greater granular debris (mean, $93 \%$ granular debris) as compared to Miller-Galante $(5.23 \mu \mathrm{m}, 15 \%)$ and anatomic porous coated designs $(1.17 \mu \mathrm{m}, 77 \%)^{31)}$. Smaller wear particles of mobile bearing designs are biologically more active and have high propensity for osteolysis ${ }^{32)}$. Bloom et al. ${ }^{33)}$ compared the complexity of revision surgery after fixed and mobile bearing UKA. They reported that $46.7 \%$ of knees required tibial augments when the primary implant used was a mobile bearing design, compared to only $11.1 \%$ of knees that required augments when an implant with a fixed bearing design was revised. In the current review, aseptic loosening was the second highest complication requiring reoperation in mobile bearing UKAs. This was probably caused by osteolysis resulting from the wear of submicron particles ${ }^{32}$. Therefore, it is worthwhile to ponder whether aseptic loosening caused by wear of submicron particles that necessitates reoperation before the wear is grossly evident.

Considering that bearing dislocation is a complication unique to mobile bearings, understanding that observed rate of zero reoperations in fixed bearings is straightforward. However, observed rate of zero reoperations of mobile bearings for wear even in studies with follow-up exceeding 17 years is intriguing ${ }^{13}$. Further research in understanding wear behavior of bearings is warranted to establish the actual effectiveness of mobile bearings in reducing wear rates.

Progression of arthritis leading to reoperation was noted at a higher frequency in mobile bearing knees as compared to fixed bearing knees. Bearing dislocations are clearly a complication unique to mobile bearings. It is likely that the two causes are in- 
terrelated, such that prevention of one predisposes occurrence of the other. Smith et $\mathrm{al}^{9}$ ) theorized that a surgeon may tend to choose a tight knee and risk slight valgus overcorrection to avoid bearing dislocation. This can result in greater contact stresses and overt loading of the lateral compartment, accelerating the progression of arthritis. Conversely, any undercorrection of deformity may have more play in the medial compartment and predispose to bearing dislocation. Perfect ligament balancing and limb alignment is, therefore, mandatory to avoid both complications, making mobile bearing UKA an unforgiving and a technically challenging procedure. The low tolerance of mobile bearings to gap mismatch even in hands of high-volume surgeons reiterates the difficulty in widespread reproduction of their results ${ }^{7}$. Fixed bearing designs permit undercorrection and may offload the lateral compartment to decelerate the progression of arthritis in the aging knee.

Wear of polyethylene insert is the principal complication requiring reoperation of fixed bearings, occurring around 8.59 years after primary surgery ${ }^{5,8,13-18)}$. Wear is a complication inherent to the design of fixed bearings, secondary to higher surface deformation and delamination in comparison to mobile bearings ${ }^{34}$. The mechanism of the polyethylene wear is different according to the type of bearing. In fixed bearings, wear of the polyethylene is caused by the fatigue and sheer stress-related mechanism. However, in mobile bearings, wear of the polyethylene is due to the abrasive and adhesive mechanism. Even though some in vitro studies based on knee stimulators report lower wear rates of fixed bearings in comparison to mobile bearings ${ }^{35,36)}$, our results suggest that higher wear rates are constantly seen in association with fixed bearing UKA, in spite of advancements in polyethylene processing and implant design.

Reoperations for persistent pain are higher for fixed bearings than mobile bearings. However, $50 \%$ of knees re-operated for persistent pain were all polyethylene UKAs of a single manufacturer reported in a single study that contributed less than $15 \%$ of the total study population ${ }^{18}$. The overall reoperation rates for persistent pain excluding the studies reporting all polyethylene UKAs are 0 for mobile bearings and 0.089 for fixed bearings. Authors of the study ${ }^{18)}$ theorized that the all-polyethylene tibial components increased load transfer to the proximal tibia, resulting in persistent bone remodeling and unexplained medial knee pain.

We recognize several limitations in this review. Due to limited availability of published RCTs, nonrandomized comparative studies were included in the analysis.

Data used for review was observational data that relied pri- marily on reporting standards, which may vary with geography, surgeon's experience and study design. Although a subgroup of studies with level I evidence would be desirable, the cumulative sample size of these studies was found to be too small to be able to reflect findings that can be extrapolated to the study population.

Use of reoperation as a measure of failure restricts inclusion of patients who elected to forgo additional surgery. Sporadic causes for reoperation, such as arthroscopy for removal of cement segments or anterior cruciate ligament tear, could not be comparatively assessed.

Constant evolution of implant design may have affected the comparability of studies separated by decades. The confounding effect of these variables on results of our analysis cannot be controlled or ruled out. In spite of these factors, most studies reported equivalent outcomes of both bearing designs, and collation of their individual data on complications has allowed this review to draw cumulative results and inferences that may have overcome effect of an individual study. The method of calculation was simplistic and differences between values compared were small, but the pattern of these differences was fairly constant within subgroups. It reiterates the effect of heterogeneity of the data and overall equivalence of outcomes, similar to the metaanalyses previously published ${ }^{9,23}$. Nevertheless, the results should be interpreted with caution.

In conclusion, the overall incidence of complications is similar for fixed and mobile bearing UKAs. The discussion of complications presented above may assist surgeons in their choice of bearing design. Further research on progression of arthritis with undercorrection in UKA, biologic activity of wear debris and mechanisms of persistent pain after UKA is desirable for improvement of outcomes and survivorship of UKA.

\section{Conflict of Interest}

No potential conflict of interest relevant to this article was reported.

\section{Acknowledgements}

The authors have no relevant financial relationships to disclose. This work was supported by meta-TFT of Korean Knee Society.

\section{References}

1. Scott RD. Mobile- versus fixed-bearing unicompartmental 
knee arthroplasty. Instr Course Lect. 2010;59:57-60.

2. Ashraf T, Newman JH, Desai VV, Beard D, Nevelos JE. Polyethylene wear in a non-congruous unicompartmental knee replacement: a retrieval analysis. Knee. 2004;11:177-81.

3. Psychoyios V, Crawford RW, O'Connor JJ, Murray DW. Wear of congruent meniscal bearings in unicompartmental knee arthroplasty: a retrieval study of 16 specimens. J Bone Joint Surg Br. 1998;80:976-82.

4. Simpson DJ, Gray H, D'Lima D, Murray DW, Gill HS. The effect of bearing congruency, thickness and alignment on the stresses in unicompartmental knee replacements. Clin Biomech (Bristol, Avon). 2008;23:1148-57.

5. Gleeson RE, Evans R, Ackroyd CE, Webb J, Newman JH. Fixed or mobile bearing unicompartmental knee replacement? A comparative cohort study. Knee. 2004;11:379-84.

6. Bonutti PM, Dethmers DA. Contemporary unicompartmental knee arthroplasty: fixed vs mobile bearing. J Arthroplasty. 2008;23(7 Suppl):24-7.

7. Bini S, Khatod M, Cafri G, Chen Y, Paxton EW. Surgeon, implant, and patient variables may explain variability in early revision rates reported for unicompartmental arthroplasty. J Bone Joint Surg Am. 2013;95:2195-202.

8. Emerson RH Jr, Hansborough T, Reitman RD, Rosenfeldt W, Higgins LL. Comparison of a mobile with a fixed-bearing unicompartmental knee implant. Clin Orthop Relat Res. 2002;(404):62-70.

9. Smith TO, Hing CB, Davies L, Donell ST. Fixed versus mobile bearing unicompartmental knee replacement: a metaanalysis. Orthop Traumatol Surg Res. 2009;95:599-605.

10. Peersman G, Stuyts B, Vandenlangenbergh T, Cartier P, Fennema P. Fixed- versus mobile-bearing UKA: a systematic review and meta-analysis. Knee Surg Sports Traumatol Arthrosc. 2014 Jun 24 [Epub]. http://dx.doi.org/10.1007/ s00167-014-3131-1.

11. Moher D, Liberati A, Tetzlaff J, Altman DG; PRISMA Group. Preferred reporting items for systematic reviews and metaanalyses: the PRISMA statement. BMJ. 2009;339:b2535.

12. Australian Orthopaedic Association National Joint Replacement Registry. Annual report 2008 [Internet]. Adelaide: Australian Orthopaedic Association; 2008 [cited 2014 Jun 4]. Available from: https://aoanjrr.dmac.adelaide.edu.au/ annual-reports-2008.

13. Parratte S, Pauly V, Aubaniac JM, Argenson JN. No longterm difference between fixed and mobile medial unicompartmental arthroplasty. Clin Orthop Relat Res. 2012;470:61-8.

14. Biau DJ, Greidanus NV, Garbuz DS, Masri BA. No difference in quality-of-life outcomes after mobile and fixed-bearing medial unicompartmental knee replacement. J Arthroplasty. 2013;28:220-6.

15. Li MG, Yao F, Joss B, Ioppolo J, Nivbrant B, Wood D. Mobile vs. fixed bearing unicondylar knee arthroplasty: a randomized study on short term clinical outcomes and knee kinematics. Knee. 2006;13:365-70.

16. Whittaker JP, Naudie DD, McAuley JP, McCalden RW, MacDonald SJ, Bourne RB. Does bearing design influence midterm survivorship of unicompartmental arthroplasty? Clin Orthop Relat Res. 2010;468:73-81.

17. Confalonieri N, Manzotti A, Pullen C. Comparison of a mobile with a fixed tibial bearing unicompartimental knee prosthesis: a prospective randomized trial using a dedicated outcome score. Knee. 2004;11:357-62.

18. Bhattacharya R, Scott CE, Morris HE, Wade F, Nutton RW. Survivorship and patient satisfaction of a fixed bearing unicompartmental knee arthroplasty incorporating an allpolyethylene tibial component. Knee. 2012;19:348-51.

19. Catani F, Benedetti MG, Bianchi L, Marchionni V, Giannini S, Leardini A. Muscle activity around the knee and gait performance in unicompartmental knee arthroplasty patients: a comparative study on fixed- and mobile-bearing designs. Knee Surg Sports Traumatol Arthrosc. 2012;20:1042-8.

20. Emerson RH Jr, Head WC, Peters PC Jr. Soft-tissue balance and alignment in medial unicompartmental knee arthroplasty. J Bone Joint Surg Br. 1992;74:807-10.

21. Kozinn SC, Scott R. Unicondylar knee arthroplasty. J Bone Joint Surg Am. 1989;71:145-50.

22. Goodfellow JW, Kershaw CJ, Benson MK, O'Connor JJ. The Oxford Knee for unicompartmental osteoarthritis: the first 103 cases. J Bone Joint Surg Br. 1988;70:692-701.

23. Cheng T, Chen D, Zhu C, Pan X, Mao X, Guo Y, Zhang X. Fixed- versus mobile-bearing unicondylar knee arthroplasty: are failure modes different? Knee Surg Sports Traumatol Arthrosc. 2013;21:2433-41.

24. Lim HC, Jung KW, Yang JH. Comparison between Unicompartmental and total knee arthroplasty in the same patient (short term results). J Korean Knee Soc. 2007;19:7-13.

25. Kim KT, Lee S, Park HS, Cho KH, Kim KS, Kim TW. Oxford phase 3 unicompartmental knee arthroplasty: minimum 5-year follow-up results. J Korean Knee Soc. 2008;20:50-7.

26. Kim KW, Nam SW, Han KY. Short term results of Oxford unicompartmental knee arthroplasty. J Korean Knee Soc. 2008;20:58-64.

27. Kim KT, Lee S, Kim TW, Lee JS, Boo KH. The influence of 
postoperative tibiofemoral alignment on the clinical results of unicompartmental knee arthroplasty. Knee Surg Relat Res. 2012;24:85-90.

28. Newman J, Pydisetty RV, Ackroyd C. Unicompartmental or total knee replacement: the 15 -year results of a prospective randomised controlled trial. J Bone Joint Surg Br. 2009;91: 52-7.

29. Newman JH, Ackroyd CE, Shah NA. Unicompartmental or total knee replacement? Five-year results of a prospective, randomised trial of 102 osteoarthritic knees with unicompartmental arthritis. J Bone Joint Surg Br. 1998;80:862-5.

30. Panni AS, Vasso M, Cerciello S, Felici A. Unicompartmental knee replacement provides early clinical and functional improvement stabilizing over time. Knee Surg Sports Traumatol Arthrosc. 2012;20:579-85.

31. Huang CH, Ho FY, Ma HM, Yang CT, Liau JJ, Kao HC, Young TH, Cheng CK. Particle size and morphology of UHMWPE wear debris in failed total knee arthroplasties: a comparison between mobile bearing and fixed bearing knees. J Orthop Res. 2002;20:1038-41.

32. Green TR, Fisher J, Stone M, Wroblewski BM, Ingham E. Polyethylene particles of a 'critical size' are necessary for the induction of cytokines by macrophages in vitro. Biomaterials. 1998;19:2297-302.

33. Bloom KJ, Gupta RR, Caravella JW, Shishani YF, Klika AK, Barsoum WK. The effects of primary implant bearing design on the complexity of revision unicondylar knee arthroplasty. J Arthroplasty. 2014;29:106-9.

34. Manson TT, Kelly NH, Lipman JD, Wright TM, Westrich GH. Unicondylar knee retrieval analysis. J Arthroplasty. 2010;25(6 Suppl):108-11.

35. Kretzer JP, Jakubowitz E, Reinders J, Lietz E, Moradi B, Hofmann K, Sonntag R. Wear analysis of unicondylar mobile bearing and fixed bearing knee systems: a knee simulator study. Acta Biomater. 2011;7:710-5.

36. Brockett CL, Jennings LM, Fisher J. The wear of fixed and mobile bearing unicompartmental knee replacements. Proc Inst Mech Eng H. 2011;225:511-9. 